\title{
Digital poesi og materialitet
}

\section{Materiel forgængelighed i Johannes Heldéns Entropi}

\begin{abstract}
"Why have we not heard more about materiality?", spørger Katherine Hayles i bogen Writing Machines $(2002,19)$. Svaret giver hun selv ved at påpege, at litterære studier har været domineret af en orientering mod indhold, hvor narrative og fiktionelle verdener er blevet behandlet, som om de udelukkende var et resultat af imaginationen. Ifølge Hayles er det i litteraturvidenskaben kommet til udtryk ved, at den traditionelt har opereret med et skarpt skel mellem repræsentationen og den teknologi, som ligger til grund for de litterære tekster. Der har med andre ord, skriver hun, været en tendens til at behandle litteratur som "immaterial verbal constructions" (ibid.). Der findes tilgange, som ikke passer ind i Hayles beskrivelse - f.eks. forskning i konkret poesi (se Invarsson og Olsson 2011) og nyere børnelitteraturforskning - og i takt med at litterære tekster også selv påkalder sig mere og mere opmærksomhed omkring deres materielle fremtrædelse, må vi formode, at litteraturvidenskabens interesse for materialitet vil vokse.

I forbindelse med digital poesi, som er denne artikels emne, ser vi en stigende tendens til, at materialiteten bliver tematiseret, både i de digital-litterære tekster og i teori om digital poesi. Jeg vil her unders $\varnothing$ ge forholdet mellem digital poesi og materialitet, og især vil jeg lægge vægt på den svenske poet Johannes Heldéns Entropi (2010), som foreligger dels som poesi i digitale medier, dels som poesi i bogform. Spørgsmålene, som skal forfølges, lyder: Hvordan forholder digital poesi sig til sin egen materielle fremtrædelse, og hvordan reflekterer den over forholdet mellem digital og trykt poesi? Sådan som jeg ser det, og som jeg skal argumentere for, lægger Entropi op til en særlig interesse for litterære mediers materialitet, og i denne sammenhæng for forholdet mellem den trykte og den digitale materialitet. Samtidig med at værket sætter fokus på sin egen materielle fremtrædelse og mediale eksistensbetingelse, som en følge af at det virker i et sammenspil mellem to medier, udfordrer det også receptionen på spørgsmålet om, hvordan det skal læses. På grund af det intime forhold mellem de to medietekster i Entropi forudsætter værket en læsning, som går tæt på de to tekster og samspillet mellem dem.
\end{abstract}




\section{To og et halvt årti og to bølger}

Digital litteratur kan defineres som litteratur "written for and read on a computer screen [and] that pursues its verbal, discursive and/or conceptual complexity through the digital medium, and would lose something of its aesthetic and semiotic function if it were removed from that medium" (Bell et al. 2010). Selv om denne definition kun er tre år gammel, kan vi allerede nu pege på flere problemer ved den, hvilket illustrerer udfordringen ved at definere en type litteratur, som både æstetisk og teknologisk modarbejder en entydig og institutionaliseret forståelse. Den digitale litteraturs form og funktionalitet er tæt knyttet til de teknologier, som betinger dens fremtrædelse. Den definition, jeg citerer ovenfor, vil derfor skulle reformuleres ganske ofte - $\mathrm{i}$ takt med at litterære tekster på nettet eller distribueret på cd-rom ændres, både som en følge af udviklingen af ny software og som et resultat af, at de litterære tekster udnytter digitale teknologier på nye måder.

Der er gået mere end to årtier, siden digital litteratur blev etableret som et fagområde med toneangivende teoretikere som George Landow, Jay. D. Bolter, Michael Joyce, Stuart Moultroup og Jane Yellowlees Douglas, og efterfølgende Espen Aarseth. Siden da har man kunnet identificere nogle udviklingstræk i den teoretiske interesse for digital litteratur. Noget forenklet kan man i kronologisk rækkefølge opstille to tendenser i teoriudviklingen og -interessen, som jeg herefter vil referere til som to bølger. Den første bølge anlagde et overordnet perspektiv på den digitale litteratur og var især optaget af generelle emner om digitale medier, nye programmer og platforme for skrivning, ligesom den diskuterede taksonomier for nye tekstgenrer. Man kiggede f.eks. i retning af poststrukturalistisk teori for at forklare de nye former for litteratur, som dukkede op på computerne. Dette var teoretiske udforskninger af forholdet mellem hypertekst og Roland Barthes' "writerly text", Deleuze og Guattaris "rhizome" og Derridas "decentralisering" (se f.eks. Delany and Landow 1991; Burnett 1993; Landow 1994; Bolter 2001). Her anså man hypertekstteknologier for at bane vejen for en endelig materialisering af poststrukturalistiske ideer. Landow påpeger for eksempel, at Barthes' skelnen mellem "readerly" og "writerly" tekster endelig er blevet realiseret som en følge af digital litteratur: "From the vantage point of the current changes in information technology, Barthes's distinction between readerly and writerly texts appears to be essentially a distinction between text based on print technology and electronic hypertext" (Landow 2006, 4). Set i dagens lys synes sådanne koblinger at være lige lovligt optimistiske på vegne af de nye tekstteknologier.

En mere frugtbar tilnærmelse i denne første bølge har man set, idet læseren af digital litteratur er blevet placeret i et modsætnings forhold til trykt litteratur (Coover 1992; Douglas 1992; Liestøl 1994; Simanowski 2002). I f.eks. Douglas' artikel "What hypertexts can do that print narratives cannot" bliver hypertekstlæseren sammenlignet med læseren af trykt litteratur med hensyn til de valg, som de enkelte medier tillader. På baggrund af denne form for tilgang har vi fået kundskab om nogle væsentlige forskelle mellem læsningen af konventionel, trykt litteratur og af digitale hypertekster. Alligevel fremstår denne overordnede tilnærmelse til digital litteratur også noget unuanceret, hvad angår forskelle mellem trykt og digital litteratur såvel som forskelle mellem forskellige digitale tekster. Spørgsmålet om 
multilinearitet og ikke-trivielle valg $\mathrm{i}$ hypertekster er betinget ikke alene af mediet og teknologien, men også af i hvilken grad de enkelte litterære tekster åbner for en aktiv læser, som vælger sine læsestier. Mens tidlige hypertekstfiktioner netop havde som dens særpræg og særlige bidrag, at de var organiseret i komplekse netværksstrukturer med tilsyneladende uendelige valg og ingen ende, har nyere digital litteratur nedtonet interessen for de mange indgange til en fortælling. Nyere digitale værker som Robert Kendals Faith (2002), Kate Pullingers Inanimate Alice (2005-) og Flight Paths (2007) og Andy Campbells Nightingale’s Playground (2010) er i større grad lineært organiserede. Landow påpeger netop den faldende interesse for netværksstrukturer, når han noget resigneret pointerer:

6f Looking back at the brief history of hyperfiction, one is surprised to note how few works have accepted the challenge of Michael Joyce's Afternoon to create branching story lines. Joyce's linking produces what we may term branching narrators, and one would expect that more writers would have tried varieties in chronology, setting, character, and so on (Landow 2006, 265).

I slutningen af 1990-tallet har der været en række fors $\varnothing g$ på at skabe grundlag for og producere mediespecifikke analyser af digital fiktion. I maj 1999 blev det tyske nettidsskrift dichtung-digital oprettet af Roberto Simanowski for at $\varnothing$ ge publiceringen af forskning i og nærlæsninger af digital litteratur. Samme år etablerede Christian Yde Frostholm, Karen Wagner og Charlotte Hansen Afsnit P (1999-2009) på nettet. Af faglitteratur er det her relevant at nævne Simanowskis bog Interfiction (2002), som omhandler fiktionsskrivning på nettet. Det samme år udgav N. Katherine Hayles bogen Writing Machines, som blandt andet indeholdt en særdeles grundig nærlæsning af Talan Memmotts Lexia to Perplexia, og i 2003 kom Jan van Looy og Jan Baetens antologi Close Reading New Media: Analyzing Electronic Literature. Specielt Hayles' bog, samt van Looy og Baetens antologi, synes at markere starten på en ny bølge af forskning i digital litteratur, hvor man har bevæget sig fra mere generelle og overordnede perspektiver på digital litteratur til mere detaljerede og mediespecifikke læsninger. Det vil sige, at der synes at have udkrystalliseret sig en praksis, som er orienteret mod det mediespecifikke og materielle. Denne nye bølge med bottomup-tilnærelser til digital litteratur har også manifesteret sig i nyere udgivelser som Literary Art in Digital Performance (Francisco 2009), Reading Moving Letters (Simanowski et.al. 2010), New Narratives: Stories and Storytelling in the Digital Age (Page og Bronwen 2011) og Digital litteratur (Rustad 2012).

Denne udvikling kan have sin forklaring i en mere generel tendens inden for de sidste års litteraturforskning til at lægge vægt på materielle kvaliteter og sansemæssige erfaringer, hvilket Simanowsky også påpeger: "it is justified to speak of a certain trend in the German and international aesthetic discourse toward the concepts of presence, materiality, and event at the expense of interpretation and meaning" (Simanowsky 2010, 15). Samtidig kan udviklingen forklares med, at nyere digital litteratur, og især digital poesi, har fremtvunget læsninger, som tager hensyn til, hvordan den fysiske fremtrædelse af teksternes semiotiske komponenter påvirker teksternes meningspotentiale. Den forøgede opmærksomhed omkring den digitale 
poesis materialitet kan ligeledes forklares med erkendelsen af, at digitale artefakter også er materielle. Digitale medier kan rigtig nok overskride nogle tekniske, materielle og konventionelle grænser mellem forskellige medier. Det vil f.eks. sige det, som Bill Brown beskriver som en dematerialisering af gamle medier: "all media may eventually be homogenized within the hegemony of the digital" $(2010,53)$. En sådan forståelse er i tråd med nyere medieteori som Kittlers, Bolters og Manovichs påstand om, at alle medier på et niveau bliver ens, fordi alle på et niveau er reduceret til numre. Manovich fremhæver for eksempel de nye mediers materialitet i bogen The Language of New Media (1999), og herunder hvordan computerens logik påvirker produktions-, distributions- og receptionsprocesser, med andre ord koderne og programmeringsmulighederne, som konstituerer det digitale værk.

\section{"Technotext"}

Et tidligt eksempel på digital poesi, som demonstrerer materialitetens betydning for og samspil med tekstens meningspotentiale, er Robert Kendalls digt "Faith" (2002).

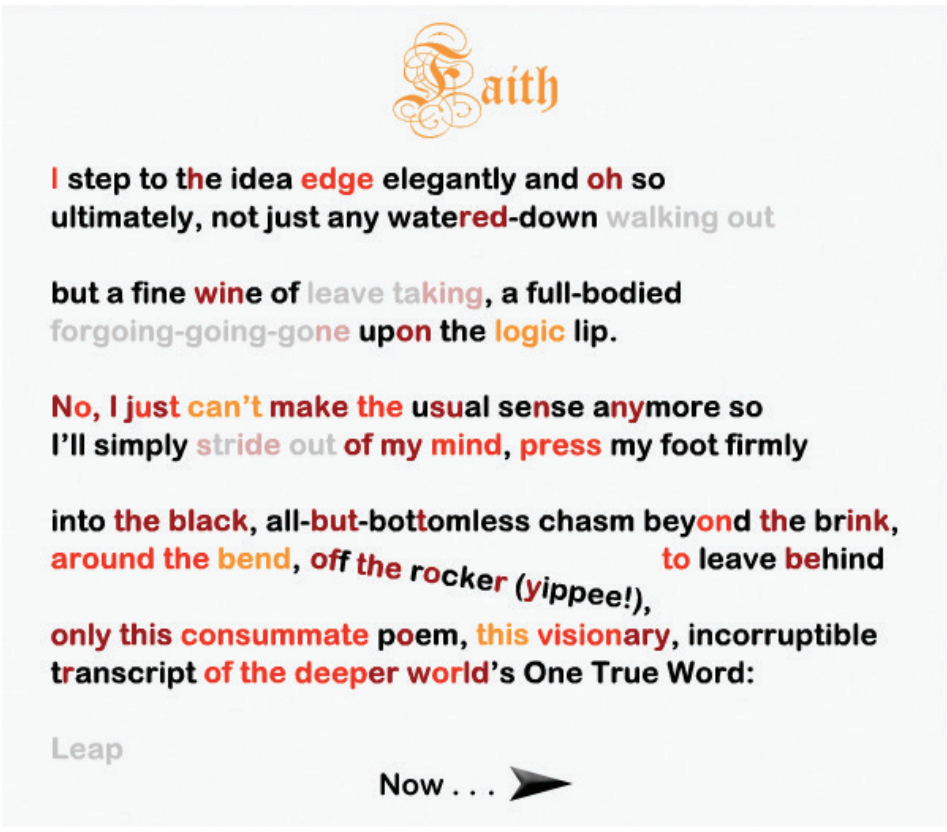

Fig. 1. Robert Kendall: "Faith", 2002. Digitalt digt i flash: http://collection.eliterature. org/1/works/kendall_faith/index.htm (C) Robert Kendall.

Digtet består af fem successivt organiserede afdelinger og tematiserer forholdet mellem tro og logik. Den første strofe lyder "Logic can't bend this", hvor pronomenet «this» både henviser til tro og til selve digtet. Den første afdeling påpeger på det lingvistiske niveau, at tro er stærkere end logik. De fire ord i afdelingen fremkommer dynamisk på skærmen. Gentagne gange falder ordet "logic" ned på titelordet "Faith", men ordene hopper væk og ud af skærmen, som om de preller af på den stærkere part, troen. Titelordet "Faith" bliver stående roligt og uberørt. Tro lader sig med andre ord ikke bøje og tøjle af logik. Udformningen af titelordet giver as- 
sociationer til ældre, autoritære skrifter, såsom Bibelen, og forstærker dikotomien mellem kristen tro og moderne videnskabslogik, mellem det gamle og varige, og det nye og flygtige, som digtet tager op.

Gennem de næste strofer fyldes digtet med stadig mere tekst, flere farver og forskellige former for bevægelse. Ordene blinker, de slås sammen, og de gennemgår forvandlinger, således at nye sammensætninger og betydningsgrundlag skabes. I fjerde strofe er der et slags klimaks og en erkendelse, som bekræfter den erkendelse, som lå i den første strofe: "No, I just can't make the usual sense anymore”. I femte strofe bryder digtets verslinjer, digtets logos, sammen, og ordet "Faith" bliver stående tilbage som det eneste, man kan have tiltro til i denne verden: "Just to sum up: Faith".

I "Faith" er der et samspil mellem ordenes betydning og måden, ordene fremkommer på skærmen, og dette samspil er af betydning for forståelsen af digtet. Digtet får en form for performativitet som følge af dets fremtrædelse, samtidig med at det skaber opmærksomhed omkring dets materielle og mediale betingelser, dvs. betingelserne for det digitale digts visuelle fremtrædelse. Dermed problematiserer digtet i selve sin væremåde skellet mellem visualitet, materialitet og medialitet, og det demonstrerer, hvordan disse tre strata spiller sammen i digtets fremtrædelse. Selv om det i praksis vil være umuligt at adskille materialiteten fra perceptionen af en tekst, sådan som også Elleström påpeger $(2010,15)$, er "Faith" et tidligt og godt eksempel på, hvordan digital poesi udnytter det digitale medies materialitet i ordenes visuelle fremtrædelse. Udforskningen af materialiteten er også et markant træk ved det sidste årtis digitale poesi. I Deena Larsens poetiske tekst Firefly (2003) er fremtrædelsen og læserens interaktion med verselinjerne fremhævet for at vise betydningen af samspillet mellem læseren, digtets mening og dets materielle dimension. Og i Andy Campbells Nightingale's Playground (2010) er ord og sætninger organiseret på en sådan måde, at de visuelt er med til at forme den verden, som hovedpersonen og det lyriske jeg bevæger sig rundt i ved hjælp af læseren.

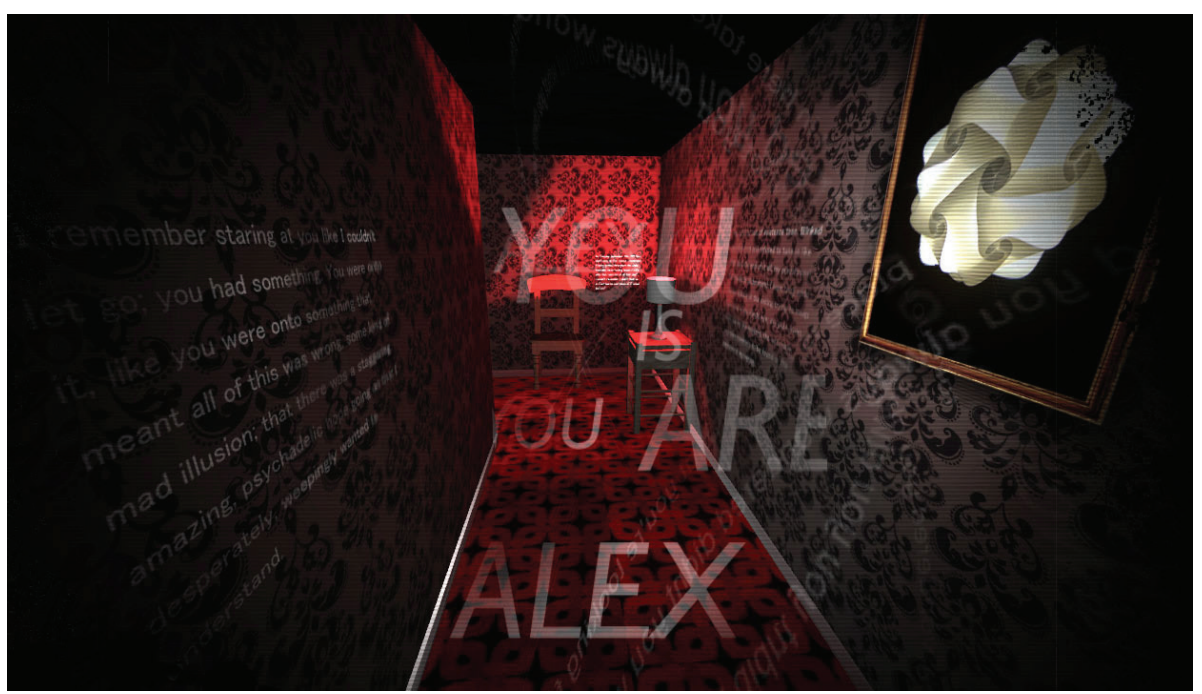

Fig. 2. Andy Campbell og Judi Alston: Nightingale's Playground, 2012. Digital fortælling i flash: http://www.nightingalesplayground.com/ (C) Andy Campbell og Judi Alston. Dreaming methods. 
Nightingale's Playground kan karakteriseres dels som en poetisk, dels som en narrativ tekst. Teksten stiller spørgsmål ved forholdet mellem minder og virkelighed, og den viser, hvordan hukommelsen former vores forståelse af fortidige og nutidige hændelser. I en af de mere poetiske dele kan læseren styre jeg-personen, som i et "first person shooter-spill", gennem gange og rum i et hus, hvor ord og sætninger hænger løst i luften eller ligger gemt i taget, væggene og gulvet. Gangene og rummene bliver visuelle metaforer for hjernens rum, som er fyldt med minder, og ved at besøge disse minder fra fortidige hændelser fremkommer der et billede af fortiden for læseren og jeg-personen; et billede som er noget anderledes, end sådan som jegpersonen oprindeligt huskede fortiden. I begyndelsen af Nightingale's Playground leder jeg-personen efter en tidligere barndomsven ved navn Alex. Men efterhånden som jeg-personen søger i minderne, og læseren læser teksten, bliver det klart, at jeg-personen og Alex er én og samme person. Identifikationen mellem jeg-personen og Alex får en parallel i det sammenfald, som finder sted mellem læseren og jegpersonen gennem førstepersons synsvinklen og handlingsperspektivet.

Litteratur, hvor tekstens materielle side spiller en væsentlig rolle i betydningsdannelsen, og/eller teksterne reflekterer over de materielle betingelser for deres fremtrædelse, betegnes af Hayles (2002) som technotext. Hun definerer teknotekster som tekster, der sammenkobler teksternes semiotiske konstruktioner med de teknologiske og materielle betingelser for deres fremtrædelse: "Literary works that strengthen, foreground, and thematize the connections between themselves as material artifacts and the imaginative realm of verbal/semiotic signifiers" (ibid., 25). Teknotekster denoterer således bestemte tekster, som tematiserer materialitetens betydning, men skal også forstås som en betegnelse for en bestemt optik, fordi den repræsenterer en udvidelse af litteraturvidenskabens praksis. Hayles kalder til og med det perspektiv, som åbner for at se teksterne og deres materielle fremtrædelse i samspil med hinanden, for en komplet model for forståelse af litteratur: "Technotexts play a special role in transforming literary criticism into a material practice, for they make vividly clear that the issue at stake is nothing less than a full-bodied understanding of literature" (ibid., 26).

I tilknytning til digital poesi (og digital litteratur) kan materialitet relateres til forskellige tekstlag, dvs. forskellige materielle lag. Materialitet kan f.eks. henvise til den teknologi, hvormed teksterne fysisk er indskrevet, og materialitet kan spille på en litterær teksts fysiske manifestation, dvs. det som gør den litterære tekst tilgængelig for vores sanser. For en konventionel tekst, som er trykt på papir, vil der ikke være nogen (væsens)forskel mellem disse to niveauer af materialitet, da indskrivningen af teksten er gjort på det samme medie og med det samme materiale, som vi sanser teksten på og gennem. I en digital tekst vil det derimod være hensigtsmæssigt at operere med flere niveauer af materialitet. Et niveau er den indskrivning, som sker på computerens harddisk, og som manifesterer sig i fysiske spor aftegnet på en magnetskive. Matt Kirschenbaum kalder denne fysiske indskrivning for "forensic materiality" og påpeger hermed, at digitale informationer er akkurat lige så fysiske og materielt varige som indskrivninger på sten eller papir.

Et andet materialitetsniveau er knyttet til tekstens overflade. Materialitet kan her blive forklaret som for eksempel "the latent corporeal interface" (Elleström 
2010, 17), eller som "de sinnliga faktorer som påverkar vår läsning af en text" (Hertzberg 2011, 5). I deres definitioner fremhæver såvel Lars Elleström som Fredrik Hertzberg, at materialiteten er de overfladestrukturer, som vores sanser møder i tilnærmelsen til en tekst. Det er med andre ord dér, den sanselige interaktion mellem tekst og læser finder sted. For digital poesi kan det også være hensigtsmæssigt at skelne mellem tre niveauer af materialitet: verbalsprogets materialitet, interfaceets materialitet og mediets materialitet (se f.eks. Bouchardon 2010). En sådan skelnen inviterer til en trefaset analyse, hvor de materielle egenskaber i en tekst, som kan tilskrives software og computer, i de tilfælde hvor det er muligt, kan adskilles fra tekstens øvrige materielle lag. Hayles' materialitetsbegreb er ligeledes orienteret mod tekstens overflade, men hun fremhæver, at materialiteten også må forstås som et selektivt fokus rettet mod bestemte fysiske aspekter ved en tekst. Der er da tale om nogle bestemte egenskaber, som ikke kan forudbestemmes, men som bliver til i samspillet mellem computeren, platformene, teksten, forfatteren og læseren. Materialiteten skal her forstås som noget, der sker, en hændelse, ikke noget, som eksisterer eller $e r$.

Hayles' pointe er, at teknoteksternes indhold og tematik går i ét med materialiteten, så indholdet og tematikken ikke kan adskilles fra materialiteten. Således bliver Writing Machines en bog, som fremhæver materialitetens betydning for meningsskabelsen i mødet med litterære tekster, og et opråb om behovet for mediespecifikke analyser. Dette sidste er selvsagt ikke noget nyt. Denne form for analyser har man bedrevet i kunsthistorien og i editionsforskningen i lang tid, men Hayles' pointe er, at et medie- og materialitetsperspektiv i høj grad har været fraværende i litteraturvidenskaben.

\section{Heldéns Entropi}

Johannes Heldéns Entropi (2010) udforsker (en uventet) dialog eller symbiose mellem poesi i henholdsvis digitale medier og bogform gennem samspillet mellem to poetiske teksters specifikke materialitet. Entropi består af en trykt bog med tekst, foruden et fotografi på bogens for- og bagside, og en digital del på en cd med tekst, grafik, lyd og dynamiske elementer. Gennem samspillet mellem de to tekstdele fremhæver Entropi, hvordan deres respektive fysiske former spiller ind på, hvad ordene og andre semiotiske komponenter betyder. Entropi demonstrerer også, hvordan det nye medie ikke følger efter et gammelt medium (bogen) og ikke kun remedierer gamle medier. I stedet opløses sådanne dikotomier, idet værket kaster nyt lys over det gamle bogmedie og viser, hvordan bogen og det digitale medie kan virke sammen. Her bevares og fremhæves bogens kompleksitet og materielle specificitet, samtidig med at de to medier, som er i spil, informerer hinanden. I samspillet mellem bogen og det digitale viser Entropi mediernes og materialitetens betydning såvel for fremtrædelsen af det poetiske som for fortolkningen af de to tekstdele.

Den digitale del giver indtryk af at være bygget op af forskellige lag. På overfladen svæver hvide prikker omkring på skærmen. Prikkerne forsvinder, hvis læserne klikker på dem, og bliver erstattet af ord og tekstfragmenter. Nogle ord og fraser udgør statiske tekstdele formet som digte, der bliver stående på skærmen, mens andre 
ord og fraser fylder den nedre del af skærmen, idet de udgør en dynamisk tekst, som i et roligt og behageligt tempo bevæger sig ind og ud af skærmbilledet.

Baggrunden veksler mellem at være sort og at fremvise en forvrænget fremtidsverden. I denne verden er der konstruktioner og veje, der danner komplekse strukturer af indgange og udgange, på kryds og tværs.

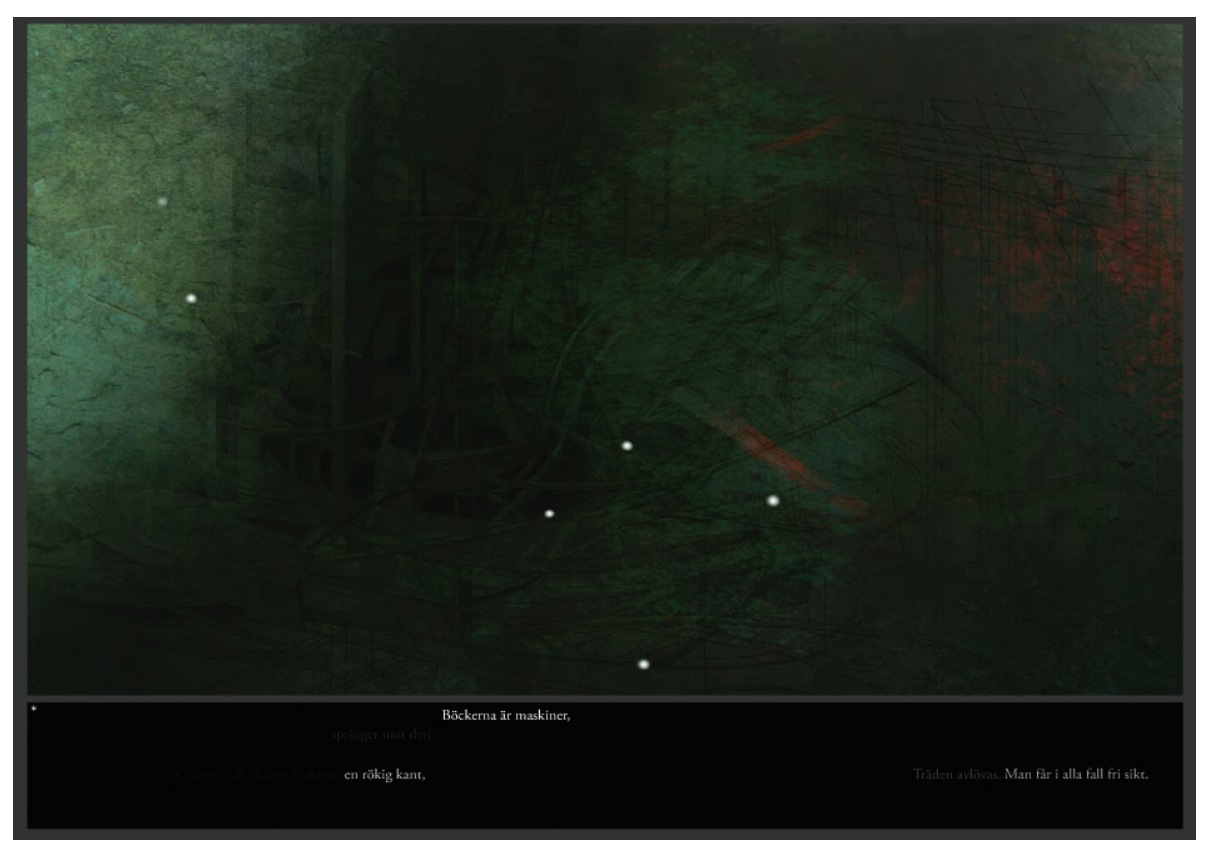

Fig. 3. Johannes Heldén: Entropi, 2010. Digitalt digt i flash, cd-rom. C) Johannes Heldén. OEI editör.

I lighed med mange af Heldéns tidligere performative og digitale tekster har Entropi en dyster karakter. Teksterne bærer noget urovækkende i sig; en stemning, der med sit kolde udtryk har en stærk følelsesmæssig appel.

Den verden, som er i baggrunden af Entropi, giver associationer til en tidligere digital tekst af Heldén, Primärdirektivet (2008). Primärdirektivet fremviser i lighed med Entropi billeder af en fremtidsverden, samtidig med at læserne kan navigere rundt i skærmbilledet og fremkalde fragmenter af en poetisk tekst. Billederne repræsenterer også en kunstnerisk etableret måde at fremstille en urban dystopisk verden i social krise, sådan som vi ser det i Fritz Langs science fiction-film Metropolis (1927). Samtidig er verdenerne i Primärdirektivet og Entropi forvrængede og kontrastfyldte, med visuelle ligheder til Giovanni B. Piranesi tegninger, som er præget af perspektivforskydninger (se også Engberg 2010).

I Entropi bruger Heldén blandt andet billede af en uddød skov og en industrialiseret fremtidsverden for at illustrere, hvad vi har i vente. De poetiske tekster, både i bogen og på skærmen, er i samklang med den verden, som er visualiseret. For eksempel står det et sted "fortfarande öde", med "(soppåsar kanyler sönderslagna bänker)" og "hypermodern strålning industriområde osynlig." Det er en tidlig morgen, som beskrives. Der er stille, og motorvejen er tom for biler. Landskabet er præ- 
get af forfalden industri, døde dyr (“överkörda grävlingen”), affald, kanyler og ødelagte bænke. Beskrivelserne fremmaner et billede af en stillestående, afventende verden. Den mørke skærm, de monotone lyde og beskrivelsen af en verden, som er langt fra vor egen virkelighed, giver Entropi et dystopisk præg.

Vi kan således sige, at Entropi portrætterer en civilisation efter en omfattende katastrofe eller som et resultat af en teknologisk og industriel udvikling, hvor naturens resurser er udnyttet til sidste dråbe. Titlen antyder, at uanset hvor store anstrengelser, man lægger i udviklingen af civilisationen, vil den nå til et slutpunkt. I fysikken bruges entropi som et mål for graden af uorden eller forandringer i et system - deraf navnet, som er sammensat af "en" (indre) og "trope" (forandring). Titlen Entropi refererer hermed til termodynamikkens anden lov, hvor entropi angiver mængden af energi, som er tilgængelig for at kunne udføre et arbejde. Ifølge denne lov vil mængden af energi i et system være konstant eller faldende. Denne udvikling er irreversibel og peger på, at naturen ikke er et uudtømmeligt reservoir, og at den tilgængelige energi i verden vil blive opbrugt. Det lyriske jeg synes da også at have accepteret sin skæbne: "kanske inte längre rädd för att försvinna." Konklusionen i verbalteksten er dystopisk: "även detta försvinner" og "ingen lösning bakåt i tiden ingen i framtiden."

\section{Entropi som "technotext"?}

I det digitale billede er der som nævnt kugler af lys, der flyver hen over skærmen. Disse kan siges at repræsentere de energiudladninger, som de poetiske tekster omhandler både i bogen og på skærmen, men lysene giver også positive konnotationer, idet de bryder gennem de ellers mørke og dystre billeder. Lyspunkter repræsenterer ofte håb og fremtidstro og er blandt andet velkendte i religiøst motiverede malerier fra 1600-tallet, så som Rembrandt van Rijns Stormende landskab (1638), Møllen (1645-48) og Tre kors (1653). I Entropi giver lyskilderne ingen religiøse antydninger om, at redningen ligger i noget oven for eller uden for os selv, men de repræsenterer et håb, idet alt ikke er slut endnu, og der måske findes andre måder at skabe energikilder på.

Vi kan herefter spørge: På hvilken måde reflekterer Entropi over sine mediale og materielle betingelser, eller hvordan er forholdet mellem tematikken entropi og verket Entropi? Som jeg har anført, handler Entropi om faktiske processer og fremviser faktiske hændelser. Samtidig er den digitale del af værket en form for proces. Det at forstå digital poesi mere generelt som en begivenhed er blandt andet fremhævet af Maria Engberg i ph.d.-afhandlingen Digital poetry (2007). Hun skriver, at den digitale lyriks rumlige og temporale særtræk gør den til både et objekt og en begivenhed, og at vi derfor står over for en ny form for lyrik, som hun kalder 'digtbegivenhed' ("poemevent"). Det kan diskuteres i hvilken grad det er nyt, at poesi indebærer faktiske begivenheder. Digtoplæsning og andre former for digt-performance kan også betragtes som 'digtbegivenheder'. Alligevel er sådanne faktiske begivenheder af relevans for forståelsen af digital poesi. I Entropi kommer disse begivenheder til udtryk i tekstens bevægelser, for eksempel ved at ord og andre semiotiske resurser er dynamiske, og ved at den digitale tekst skiftevis fremtræder på lys og mørk baggrund. 
Men Entropi er som 'digtbegivenhed' karakteristisk ved, at den gentages kontinuerligt. Verdenen, som visualiseres i baggrunden, fremkommer igen og igen uden ændringer, og det samme gør den monotone lyd, som forløber i en sløjfe. Den digitale del af Entropi har ingen ende. Læserne kan når som helst starte på ny og være vidne til de samme begivenheder. Tekstens form fremviser således ikke forandringer, men begivenheder som repeteres. Fænomenet entropi foregår derimod over tid og handler om forandring, og det drejer sig da om forandringer i retning af kaos og uorden. Så længe tid ikke kan reverseres, kan fænomenet entropi heller ikke reverseres. På denne vis bliver entropi en lov om irreversibilitet og om det ikke-gentagelige. Derfor har entropien som en mulig tematik i Entropi ikke noget korrelat i tekstens form. Tilsvarende er Entropi i sin form ikke regressiv, idet de forskellige ord og fraser til slut fremtræder på skærmen. Nogle af fragmenterne fremstår til og med som faste, som om de er stabiliserede i en traditionel lyrisk form. Begivenhederne og forandringerne er stoppet op, det samme er 'digtbegivenhederne'. Fragmenterne er låst fast på skærmen og er tilgængelige for fortolkning, ikke bare én gang, men ved hver læsning af Entropi. Den digitale tekst er med andre ord stabil og permanent, og i den forstand afviger teksten fra det, den forsøger at tematisere.

Derimod kan vi beskrive samspillet mellem bogen og den digitale del som entropisk, fordi det ikke kan afgrænses til eller tvinges ind i en stabil form eller et fast mønster. Forholdet mellem de to medietekster er ikke nødvendigvis kaotisk, men som læsere kan vi aldrig nå tilbage til et oprindeligt, originalt forhold mellem de to.

\section{Imitation og intensivering}

Som en tekst, der kombinerer to medier, hvor begge er repræsenteret gennem deres egen materialitet og deres egen mediespecificitet, aktualiserer Entropi spørgsmålet om, hvordan vi kan forstå forholdet mellem de to medier. Og måske også i hvilken rækkefølge de skal læses. Her er det ikke sådan, at den ene del skal læses som en videreudvikling af den anden. Vi ved ingenting om, hvilke af dem der er lavet først. Det er ikke tale om en adaption eller en remediering. Ej heller er det en ekfrase, dvs. en tekst som er skrevet over et billede. I stedet kan vi sige, at de to medier er smeltet sammen på en sådan måde, at Entropi ikke eksisterer foruden samspillet mellem dem.

I sin diskussion af forholdet mellem trykte og digitale medier skriver Hayles, at digital litteratur vil være en betydelig komponent i 2000-tallets litterære kanon (2008, 159). Hun argumenterer for sit synspunkt ved at påpege, at det meste af samtidslitteraturen allerede er berørt af digitale medier, fordi den har eksisteret som elektronisk fil i tidspunkter af sin tilblivelsesproces, hvis ulige etaper alle er "modes of signification." Hayles mener altså, at til trods for at megen litteratur fortsat forekommer i bogform, så har det digitale på forskellige måder efterladt sig spor i den trykte form. Dette kan have at gøre med nye muligheder for typografisk udformning af en tekstside, eller med at nye typer bogomslag er muliggjort på grund af ny teknologi og ny software.

Hayles foreslår, at forholdet mellem trykt litteratur og digital litteratur kan forstås gennem to komplementære strategier, imitation og intensivering (ibid., 162). 
Imitation indebærer, at en tekst efterligner et andet mediums materialitet. Dette kan ske gennem forskellige former for remediering, hvor et medium skaber en illusion om at være noget andet og dermed giver indtryk af at have andre materielle kvaliteter, end det er tilfældet. Intensivering indebærer, at medier fremhæver deres særegenheder og egen materialitet, det vil sige det, som gør, at de aktuelle medier kvalitativt adskiller sig fra andre medier; det, som gør dem anderledes, deres affordanser, kunne man måske sige.

Imitation og intensivering manifesterer sig i Entropi i de to deles materialitet. I den poetiske tekst, som dannes nederst på skærmen, pulserer fragmenterne $\mathrm{i}$ et tempo, som harmonerer med lysenes rolige bevægelser hen over skærmen. Til tider er fragmenterne læselige, til tider nedtones de og bliver usynlige, før de igen toner frem på skærmen. Dette visuelle udtryk genfinder vi i bogen, men her er grafiske virkemidler benyttet for at skabe en illusion om dynamik og pulsering; en teknik og strategi, som kan minde om den litterære avantgarde og senere neo-avantgardens brug af typografiske virkemidler for at skabe en illusion om bevægelige ord og bogstaver.

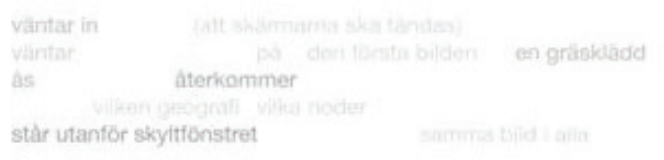

disig höst springer i villaomrädet gräluvtroja helluset snant stiärnklar natt ryker om andedräkten tiltvaro tillvaron sammagfatta d

Fig. 4. Johannes Heldén: Entropi, 2010. Digt i bog. (C) Johannes Heldén. OEI editör.

Ord er markeret i forskellige gråtoner, nogle er stærkt fremhævet, andre svage og næsten ulæselige. Vi kan tolke brugen af forskellige gråtoner og de tomme rum mellem nogle af fraserne, som om ordene er i færd med at forsvinde eller allerede er forsvundet fra papirets overflade, måske som følge af at energien gradvis tappes fra systemet. Det er som om, bogsiderne er blevet behandlet med lyssensitive kemikalier, som gør, at ordene gradvis forsvinder, når de bliver udsat for lys. Bogsiderne korrelerer da med energiudladningerne og forfaldet, som beskrives i teksterne. Vi bliver ikke bare præsenteret for en verden, som er i færd med at bryde sammen, bogtekstens eksistens er også truet.

\section{Bogtekstens forgængelighed?}

William Gibson og Dennis Ashbaughs bog Agrippa (a book of the dead) (1992) er et velkendt projekt om litterære mediers materielle forgængelighed. Agrippa består af 
en digital del og en bog, hvor skriften ved hjælp af forskellige teknikker forsvinder, når den bliver læst. I den digitale del bliver teksten slettet efter førstegangslæsningen, og ordene og sætningerne i bogen forsvinder bogstavelig talt, idet de bliver udsat for lys. En tilsvarende tematisering af det materielt forgængelige kan vi læse ud af Entropi. Bogtekstens visuelle udtryk er et varsel om bogtekstens død, om at alt kommer til at forsvinde. Vor kulturelle skriftarv, alt som er lagret i bogform, vil en gang i fremtiden forvitre og blive borte. I modsætning til dette fremstår det digitale overraskende nok som en slags redning. Vi opfatter det normalt sådan, at vi gør os selv sårbare, hvis vi bevarer og lagrer vores kunst og kultur ved hjælp af numeriske repræsentationer og digitale programmeringskoder. Denne myte reflekteres i film som The Matrix (1999), i teoretiseringer over digitale medier som ustabile eller "unfinished business", som Peter Lunenfeld (1999) kalder det, eller i daglig tale når vi siger, at "det som står på nettet i dag, er borte i morgen."

I Entropi forsvinder det digitale ikke. Tværtimod viser det digitale sig at være meget standhaftigt og varigt tilgængeligt. Ordene kommer igen og igen, det samme gør billedet i baggrunden, og lyden går i loop. Og teksterne kan som nævnt genlæses. I stedet for bogtekstens materielle, lineære udvikling mod udslettelse og evigt tab, reflekterer den digitale del en cirkularitet, en evig gentagelse af det samme, forstået som en produktiv reproduktion, der overskriver det lineære og en status som en eventuel kopi af bogen.

Hvilket forhold er der så mellem de to deles materialitet i Entropi? Vi kan sige, at i den digitale del af Entropi er ideen om bevægelige ord remedieret, og således imiterer den strategier fra trykt litteratur. Men en remediering i digitale medier vil også involvere processer, hvor det nye medies muligheder udnyttes. Således fremhæves det nye medies særegenheder også. Det betyder, at den skriftlige tekst ikke bare skaber en illusion om bevægelse, men at ord og fraser faktisk bevæger sig. Dermed er den digitale tekst ikke kun en imitation af den trykte tekst; den er samtidig en intensivering af den digitale form og en fremhævelse af de digitale mediers muligheder. Men vi kan også sige, at bogteksten bærer spor af det digitale i sig; at den efteraber den dynamiske tekst på skærmen. De to dele fremstår med andre ord som en imitation af hinanden, men det er uklart og usikkert, hvilken der imiterer, og hvilken som bliver imiteret. Denne ubestemthed fremhæver Hayles i sin forståelse af intermedialitet som heteroarki $(2008,45)$. Hayles forklarer det sådan: "Because these interactions go up as well as down, down as well as up, such a system might more appropriately be called a 'dynamic heterarchy'." Begrebet "heteroarki" henviser altså til, hvordan medier indgår i hinanden på måder, som gør, at vi ikke kan placere det ene medie før, over eller som mere vigtigt end det andet. Således foreslår hun en opløsning af hierarkisk tænkning i forbindelse med mediale interaktioner samt - sådan som jeg ser det - en ophævelse af kronologiens relevans. Dermed skal imitation og intensivering ikke forstås som reduktionistiske mål ved tilnærmelser til intermediale samspil, men som analytiske begreber for at forstå komplekse intermediale og semantiske samspil. I en sådan forståelse af intermedialitet er bog-teksten ikke et (platonisk) ideal, som den digitale tekst stræber mod, snarere bevæger de to medier og de to tekster sig på samme tid mod hinanden og fra hinanden. 
Entropi er et værk, som bliver til i grænsefeltet mellem medier og deres materialitet. I samspillet mellem de to medier bliver værket flygtigt og vanskeligt at fastholde gennem entydige læsninger. Således bliver det i form og indhold en hændelse, en tilstand som altid er i bevægelse. I tilnærmelsen til digital litteratur, såvel som dens intermediale praksis, er der en tendens til, at man opbryder grænserne mellem medier og gør dem ubetydelige - og dermed overser det materielt specifikke. Entropi viser den potentielle effekt af intermediale praksisser, i samspillet mellem trykt og digital litteratur, og at denne effekt altid på en eller anden måde er baseret på mediale grænser og forskelle.

Sådan som jeg opfatter det, viser Entropi, hvordan litteratur i bogform og digitalt kan virke sammen, idet begge litterære tekster er præsenteret og repræsenteret gennem deres respektive medier og deres specifikke materialitet. Dermed passer værket ikke fuldstændigt ind i nogen af de fire generationer af digital litteratur, som jeg henviste til indledningsvis. Og dermed bevidstgør det os om de konventionelt og teknisk skabte mediegrænser og fremtvinger en bevægelse væk fra taksonomi-tænkningen for digital litteratur og i retning af de mere kreative og dynamiske potentialer, som ligger i digitale medier og i samspillet mellem litteratur i forskellige medier.

Den eneste måde litteratur i bogform og på skærmen kan fungere sammen, uden at den ene får forrang frem for den anden og der opstår et hierarkisk forhold mellem de to, er ved, at de begge bevarer hver deres materialitet. Det vil sige, at de forskellige medieformer i Entropi er til stede gennem deres egen materialitet og deltager i konstitueringen og betydningsdannelsen af hele det performative værk på deres egne mediespecifikke måder. Måske kan man sige, at Entropi demonstrerer en co-udvikling, det vil sige, at bogen og det digitale indgår i en kontinuerlig reciprok kausalitet.

Entropi overskrider derfor dikotomien mellem bogen og computeren ved at vise eller søge mod måder, som trykte og digitale former virker sammen på udover subjekt-objekt-relationer eller dominant-domineret-dikotomier. Værket udforsker grænserne mellem medier og mellem kunstformer, og således opfinder eller genopfinder det medier for sådanne komplekse former for litteratur og kunst.

Oversat af Louise Mønster

\section{Litteratur}

Bell, Alice et.al. (2010): “A [S]creed for Digital Fiction“, i Electronic Book Review: http://www.electronicbookreview.com/thread/electropoetics/DFINative.

Bolter, Jay D. (2001): Writing Space: Computers, Writing and the Remediation of Print (second edition). New Jersey: Lawrence Erlbaum Associates Publishers.

Bouchardon, Serge (2010): «The Aesthetic of Materiality in Electronic Literature". Sidst læst 24.01.13: http://www.utc.fr/ bouchard/articles/bouchardon-bergen-materiality.pdf.

Brown, Bill (2010): "Materiality", i W.J.C. Mitchell og Mark B. N. Hansen (red.): Critical terms for Media Studies. Chicago: The University of Chicago Press, s. 49-63.

Burnett, K. (1993): “Toward a Theory of Hypertextual Design”, i Postmodern Culture 3(2).

Campbell, A. and Alston, J. (2012): Nightmare's Playground. Last accessed 13 December 2012 at URL: http://www.nightingalesplayground.com/.

Coover, R. (1992): “The End of Books.” New York Times Book Review (June 21, 1992) 1, s. 23-24. 
Delany, P. and Landow, G. P. (1991): Hypermedia and Literary Studies. Cambridge: MIT Press. Douglas, J. Y. (1992): "What Hypertexts Can Do That Print Narratives Cannot." Reader: Essays in Reader-Oriented Theory, Criticism, and Pedagogy 28, s. 1-22.

Elleström, Lars (2010): “The Modalities of Media. A Model for Understanding Intermedial Relations", I Lars Elleström (red.): Media Borders, Multimodality and Intermediality, Hampshire: Palgrafe MacMillan, s. 11-50.

Engberg, Maria (2007): Born Digital. Writing Poetry in the Age of New Media. Dr.afh. Uppsala Universitet.

Engberg, Maria (2010): "Prime Directive / Primärdirektivet”. Sidst læst 21.02.13 på: http:// directory.eliterature.org/node/398.

Gibson, William og Dennis Ashbaugh (1992): Agrippa (A Book of the Dead). New York: Kevin Begos.

Hayles, N. Katherine (2002): Writing Machines. Cambridge. MIT Press.

Hayles, N. Katherine (2008): Electronic Literature. New Horizons for the Literary. Notre Dame: University of Notre Dame Press.

Hertzberg, Fredrik (2011): "Materialitet i digital miljö», i Aiolos, 42/2011, s. 5-8.

Heldén, Johannes (2010): Entropi. Stockholm: OEI.

Invarsson, Jonas og Jesper Olsson (red.) (2011): Media and Materiality in the Neo-Afantgarde. Frankfurt am Main. Peter Lang Verlag.

Kendal, Robert (2002): Faith. Sidst læst 23.01.13 på: http://collection.eliterature.org/1/ works/kendall_faith/index.htm.

Landow, George P. (1994): "What's a Critic To Do? Critical Theory in the Age of Hypertext", i George P. Landow (red.): Hyper/Text/Theory. Baltimore, MD: John Hopkins University Press, s. $1-48$.

Landow, George P. (2006): Hypertext 3.0: Critical Theory and New Media in an Era of Globalization. Baltimore, MD: John Hopkins University Press.

Larsen, Deena (2006): Firefly. Sidst læst 23.01.13 på: http://www.poemsthatgo.com/gallery/ fall2002/firefly/index.html.

Liestøl, Gunnar (1994): “Wittgenstein, Genette, and the Reader's Narrative.” I George P. Landow (ed.): Hyper/Text/Theory. Baltimore, MD: John Hopkins University Press, s. 87-120.

Lunenfeld, Peter (1999): The Digital Dialectic. New Essays on New Media. Cambridge, MIT Press. Manovich, Lev (1999): The Language of New Media, Cambridge: MIT Press.

Pullinger, K. and Joseph, C. (2007): Inanimate Alice. Sidst læst 13. juli 2012 på: http://www. inanimatealice.com/

Page, R. and Thomas, B. (eds.) (2011): New Narratives: Stories and Storytelling in the Digital Age. Lincoln, NE: University of Nebraska Press.

Pullinger, K., Joseph, C. and participants. (2010): Flight Paths: A Networked Novel. Sidst læst 13. juli 2012 på: www.flightpaths.net.

Rustad, Hans Kristian S. (2012): Digital litteratur. En innføring. Oslo: Cappelen Damm Akademiske.

Simanowski, R. (2002): Interfictions: Vom Schreiben im Netz. Frankfurt a. M.: Suhrkamp

Simanowski, Roberto et.al. (2010): Reading Moving Letters. Digital Literature in Research and Teaching. Bielefeld: Transcript Verlag.

Van Looy, J. and Baetens, J. (eds.) (2003): Close Reading New Media: Analyzing Electronic Litera- 